\title{
Neural correlates of Mystical Experience
}

Irene Cristoforiab, Joseph Bulbulia ${ }^{c}$, John H. Shaver ${ }^{c}$, Marc Wilson ${ }^{d}$, Frank Kruegeref, and Jordan Grafman ${ }^{\text {abg }}$

${ }^{a}$ Cognitive Neuroscience Laboratory, Brain Injury Research, Rehabilitation Institute of Chicago, Chicago, IL, 60611, USA

${ }^{b}$ Department of Physical Medicine and Rehabilitation, Feinberg School of Medicine Northwestern University, Chicago, IL 60611, USA

c School of Art History, Classics and Religious Studies, Victoria University of New Zealand, Wellington, 6140, NEW ZEALAND

d Department of Psychology, Victoria University of New Zealand, Wellington, 6012, NEW ZEALAND

e Molecular Neuroscience Department, George Mason University, Fairfax, VA, 22030, USA

f Department of Psychology, George Mason University, Fairfax, VA, 22030, USA

9 Department of Neurology, Feinberg School of Medicine Northwestern University, Chicago, IL 60611, USA

Contact information:

Jordan Grafman, $\mathrm{PhD}$

Cognitive Neuroscience Laboratory

Brain Injury Research Program

Rehabilitation Institute of Chicago

345 E Superior Street

60611 Chicago, USA

Email: jgrafmain@northwestern.edu

Office: 312-238-1495

Fax: 312-238-2208

Or irene.cristofori@northwestern.edu 
Abstract: Mystical experiences, or subjectively believed encounters with a supernatural world, are widely reported across cultures and throughout human history. Previous theories speculate that executive brain functions underpin mystical experiences. To evaluate causal hypotheses, structural studies of brain lesion are required. Previous studies suffer from small samples or do not have valid measures of cognitive functioning prior to injury. We investigated mystical experience among participants from the Vietnam Head Injury Study and compared those who suffered penetrating traumatic brain injury ( $\mathrm{pTBI} ; \mathrm{n}=116)$ with matched healthy controls (HC; $\mathrm{n}=32)$. Voxel-based lesion-symptom mapping analysis showed that lesions to frontal and temporal brain regions were linked with greater mystical experiences. Such regions included the dorsolateral prefrontal cortex (dIPFC) and middle/superior temporal cortex (TC). In a confirmatory analysis, we grouped pTBI patients by lesion location and compared mysticism experiences with the HC group. The dIPFC group presented markedly increased mysticism. Notably, longitudinal analysis of pre-injury data (correlating with general intelligence and executive performance) excludes explanations from individual differences. Our findings support previous speculation linking executive brain functions to mystical experiences, and reveal that executive functioning (dIPFC) causally contributes to the down-regulation of mystical experiences.

Keywords: mystical experience, religious belief, voxel-based lesion-symptom mapping, penetrating traumatic brain injuries.

Abstract word count: 189

Total word count: 6657 
"God spoke to me and His voice was as real as the person next to me." [Study

Participant]

\section{INTRODUCTION}

Tendencies to demonstrate supernatural belief are evident across all human cultures (Alcorta \& Sosis, 2005; Wildman, 2011). Mystical experiences, which can be defined as subjectively believed encounters with a supernatural being or supernormal world, are thought to underpin ordinary religious beliefs (Schjoedt, Stodkilde-Jorgensen, Geertz, \& Roepstorff, 2009). Mystical experiences can be defined as fusion with a supernatural agent (Barrett \& Keil, 1996). D'Aquili and Newberg described another model of mystical experience (D'Aquili \& Newberg, 1993). According to this model, four main phenomenological features characterize mystical experiences (a breakdown in the usual sense of the passage of time; a breakdown in the usual sense of the extension of space; a breakdown in the differentiation between objects in the external world; and a breakdown in the differentiation between the self and the external world). Mysticism has been linked with hallucinations that characterize schizophrenia or other psychiatric disorders. Saver and Rabin (1997) investigated the interplay between psychiatric disorders and mystical experiences. They suggested that religious delusions could be considered as subtypes of delusional experience in schizophrenia, mania, and depression (Saver \& Rabin, 1997). Mystical states and psychiatric illness can be difficult to distinguish since are both characterized by delusion, hallucinations, and social isolation. In addition, mystical experiences and delusional symptoms share similar brain networks involving PFC, parietal, 
and temporal cortex (Benson \& Stuss, 1990; Cutting, 1987; Ng, 2007; Previc, 2006).

Mystical experiences are characterized by a sense of timelessness and union with a supernatural entity (Stace, 1960). Despite tremendous cultural and personal importance; however, comparatively little neuroscientific research exists investigating the causal underpinnings of supernatural experiences.

To date, the cognitive neuroscience study of religious beliefs offers two plausible, but competing, hypotheses regarding mystical experience: 1) The Temporal Involvement Hypothesis, and 2) the Executive Inhibition Hypothesis. The Temporal Involvement Hypothesis suggests that mystical experiences are induced by activity in regions of the brain associated with emotion, abstract semantics, and imagery (Kapogiannis, et al., 2009). For instance, patients suffering from right temporal lobe epilepsy frequently report mystical experiences during or after seizures (Devinsky, 2003; Devinsky \& Lai, 2008; Geschwind, 1983).

By contrast, it has been theorized that executive down-regulation in response to authoritative suggestions underpins mystical experiences (Deeley, 2003). Because executive functions are supported by structural networks in frontal brain regions, the Executive Inhibition Hypothesis has been the focus of neuropsychological investigations of frontal networks, specifically the dorsolateral prefrontal cortex (dIPFC) (Newberg, Wintering, Morgan, \& Waldman, 2006; Schjoedt, et al., 2013). For instance, Schjoedt et al., 2013 theorized a reduction of cognitive resources invested in error monitoring during religious rituals (Schjoedt, et al., 2013). 
In support of the Executive Inhibition Hypothesis, Newberg et al. (2006) observed decreased activity in the dIPFC during mystical exercises in a small sample $(n=5)$ of practitioners of glossolalia (i.e., religious prayer group experiences in which individuals speaks an incomprehensible language) (Newberg, et al., 2006). Moreover, a recent study has shown that participants down-regulated regions in the dIPFC in response to prayers performed by a charismatic speaker (Schjoedt, Stodkilde-Jorgensen, Geertz, Lund, \& Roepstorff, 2011). Additionally, more recently it has been showed that the dIPFC was activated more strongly in skeptics compared to believers in supernatural phenomena (Lindeman et al., 2013), suggesting that executive functions may underpin epistemic vigilance and skepticism. These results are consistent with recent studies in which experimenter suggestions of mystical experiences were observed to affect participants' subjective reports of mystical experiences, despite administration of bogus stimuli (Andersen, Schjoedt, Nielbo, \& Sorensen, 2014).

Even if executive disinhibition has been associated with authoritative suggestions (Deeley, 2003), religious rituals (Schjoedt, et al., 2013), and glossolalia (Newberg, et al., 2006), it has not been directly associated with mystical experience.

Though it is widely agreed that mystical experiences cannot be isolated to a single brain region, the frontal and temporal cortex are known to mediate cognitive and affective functions that may be relevant to expressing or inhibiting mystical experiences (Bulbulia \& Schjoedt, 2012; Schjoedt, et al., 2009).

Even if a number of studies showed that cognitive control is supported by a large cortical network involving the dIPFC, ventrolateral prefrontal cortex, dorsal cingulate, 
and parietal cortex (Aron, Robbins, \& Poldrack, 2004; Corbetta \& Shulman, 2002), the dIPFC has been considered as a key brain structure for imposing inhibition, particularly in association with religious beliefs [i.e., (Schjoedt, et al., 2011)].

The dIPFC is involved in cognitive control (Koechlin, Ody, \& Kouneiher, 2003), and this down-regulation has been explained in terms of a reduction of cognitive resources invested in error monitoring during religious rituals (Schjoedt, et al., 2013). This could lead to a tendency to believe that certain sensorial experiences we have are mystical and due to supernatural phenomena - at least partly due to inappropriate inhibitory control (R. W. Hood, Hill, \& Spilka, 2009). Lesions to crucial networks involved in cognitive control such as the dIPFC, might influence our belief system and as a consequence increase our mystical experiences. Decreased cognitive inhibition has been found in individuals with high level of neuroticism (Nigg, 2000), altered state of consciousness (Dietrich, 2003), and bias in logic thinking (Cassotti \& Moutier, 2010) and in patients suffering from schizophrenia and obsessive and compulsive disorders (Friedman \& Miyake, 2004). All these personality traits and pathological conditions have been associated with supernatural beliefs (Brugger \& Mohr, 2008).

The goal of our study was to assess the causal contributions of brain structures that may underpin mystical experiences. To test the predictions of previously debated theories, we investigated the causal contribution of specific brain regions to reported mystical experiences in a large sample of participants from the Vietnam Head Injury Study (VHIS) who suffered from penetrating traumatic brain injury (pTBI; 116) as well as in matched combat veterans without brain injury, i.e., healthy controls $(\mathrm{HC} ; 32)$. Participants completed a subscale (M-Scale) of a well-established instrument for the 
study of mystical experience (R. W. Hood, Jr., 1975)] The M-scale refers to mystical experiences that the participants may have previously experienced (e.g. "I have had an experience that was both timeless and spaceless"). We performed voxel-based lesionsymptoms analysis (VLSM) on the total M-Scale score between our two groups. Previous studies have reported that obtaining a mystical state at will is difficult and suggested that reported mystical experiences are a reliable tool for studying mysticism (Beauregard \& Paquette, 2006; Luhrmann, 2005, 2012). We hypothesized that mystical experiences are regulated by key regions within the frontal and temporal cortex. On the one hand, we predicted that selective impairment of the dIPFC would be associated with greater mystical experiences due to the dIPFC role in regulating inhibition [e.g., (Koechlin, et al., 2003)] and evidence showing dIPFC deactivation in responses to religious authority (Schjoedt, et al., 2011), a belief in supernatural phenomena (Lindeman, Svedholm, Riekki, Raij, \& Hari, 2013), and hypnotic suggestion (Deeley et al., 2014), On the other hand, we predicted that selective lesions to the temporal cortex (TC, including superior and middle temporal gyrus) are associated with fewer mystical experiences due to the role of the temporal cortex (TC, superior and middle temporal gyrus) in generating mystical experiences (Geschwind, 1983; Devinsky, 2003; Devinsky and Lai, 2008). In this scenario, the dIPFC serves as the top-down regulator of mysticism. 


\section{MATERIALS AND METHODS}

2.1. Patients. Patients were drawn from Phase 4 of VHIS, which is a longitudinal study of American male combat veterans with $\mathrm{pTBI}$ and matched combat veterans without a history of brain injury or neurological disorder, i.e., healthy controls $(\mathrm{HC})$ [for a detailed description of the VHIS see (Dal Monte, et al., 2014; Raymont, Salazar, Krueger, \& Grafman, 2011)]. For this study, our sample of veterans included $116 \mathrm{pTBI}$ and $32 \mathrm{HC}$ participants who underwent 5-7 days of neuropsychological testing between 2008 and 2012 at the National Institute of Neurological Disorders and Stroke (NINDS) in Bethesda, MD. Participants were evaluated at the same time, approximately 40-45 years post-injury $(\mathrm{pTBI})$ and post-war experience $(\mathrm{HC})$. Both $\mathrm{pTBI}$ and $\mathrm{HC}$ were followed across the four phases of the VHIS. In addition, we tracked the onset of mystical experiences (during the injury/war or after the injury/war experience). Twentythree out of $50 \mathrm{pTBI}$ patients experienced mysticism directly after the gunshot/injury, i.e., during active duty, while none of the $\mathrm{HC}$ experienced mysticism during the war; 27 out of $50 \mathrm{pTBI}$ and 9 out of $9 \mathrm{HC}$ experienced mysticism post-war and after discharge from the military. All participants gave written informed consent that followed the Code of Ethics of the World Medical Association (Declaration of Helsinki). The NINDS Institutional Review Board approved the study.

2.2. Mysticism Scale. Mystical experiences were assessed by the Mysticism Scale, a scale with good internal consistency and construct validity [M-Scale (R. W. Hood, Jr., 1975)]. The scale consists of items including feelings of unity, sacredness, ineffability, joy, as well as a sense of transcending time and space, and an intuitive belief that the experience is a source of objective truth about reality [e.g., "I have had an experience 
that was both timeless and spaceless"; for a review see (R. W. Hood, et al., 2009)]. The M-Scale rating was measured using a 9-point Likert scale (from - 4 = definitely not true to $+4=$ definitely true), and 4 of the items of the scale were reverse-coded. A higher score on the M-Scale indicates greater mystical experiences.

To further probe the authenticity of mystical experiences reported on the M-Scale, participants were also asked to respond to open-ended questions about their previous mystical experience (i.e., Please describe your mystical experience; What was it about this experience that made you think of it as mystical?). While $43.1 \%(\mathrm{~N}=50)$ of pTBI reported mystical experiences on the open-ended questions, only $28.1 \%(\mathrm{~N}=9)$ of $\mathrm{HC}$ reported mystical experience on the open-ended questions.

2.3. Neuropsychological testing. Neuropsychological tests included the Armed Forces Qualification Test (AFQT-7A, 1960) that contains a percentile score used as a surrogate for IQ (Grafman, et al., 1988) and allowed us to measure pre- and post-injury general intelligence. The pre-injury AFQT was administered to participants at induction to the military and the AFQT was re-administered during the phase 4 evaluation. The AFQT has been standardized and its total score is highly correlated with general intelligence test scores (Grafman, et al., 1988). Neuropsychological tests included also the Token Test (TT; McNeil \& Prescott, 1994) for basic verbal comprehension; the Visual Object and Space Perception Battery (VOSP; Warrington \& James, 1991) for object and space perception; the Beck Depression Inventory 2 (BDI-2; A.T. Beck, Steer, Brown, \& 1996) for depression; and the Mississippi post-traumatic stress disorder scale (MPTSD; Keane, Caddell, \& Taylor, 1988) for post-traumatic stress disorder; the Wechsler Memory Scale-III abbreviated (WMS-III; Wechsler, 1997) for general memory; the 
Verbal Fluency task and the Sorting Test from the Delis Kaplan Executive Function System (D-KEFS; Delis, Kaplan, \& Kramer, 2001) for semantic verbal fluency and problem-solving, respectively. Additionally, we used subtests from the observer-rated Neurobehavioral Rating Scale (NBRS; Levin, et al., 1987) to control for observed disinhibition, hallucinatory behaviors, and unusual thoughts. Disinhibition, hallucinatory behaviors, and unusual thoughts severity were rated on a scale from 1 to 7 , with 1 corresponding to absence of symptom and 7 corresponding to severe symptoms.

Finally, since mystical experience has been related to temporal lobe epilepsy (Dewhurst \& Beard, 1970; Persinger, 2001), we recorded whether our participants were diagnosed with epilepsy.

2.4. Statistical analysis. Behavioral analyses were conducted using IBM @ SPSS@ 21.0 with significance levels set to 0.05 for all analyses. Data were tested for normal distribution (Kolmogorov-Smirnov test) and variance homogeneity (Bartlett's test). Data were normally distributed, and assumptions for analyses of variance were not violated. Parametric tests (independent samples t-tests and one-way analysis of variance, ANOVA) were performed between groups on the dependent variable (i.e. M-Scale) and on controls measures (i.e. neuropsychological testing). Bivariate Pearson correlations were calculated between mysticism scores and intelligence scores (pre- and postAFQT) for pTBI and HC groups. One-way ANOVA was used for the confirmatory group analysis, and we used Bonferroni correction for multiple comparisons.

The M-Scale exhibited adequate reliability (Cronbach's alpha $=0.69$ ), hence factor analysis was used to obtain each participant's factor score on the M-Scale. Factor analysis was conducted on the items of the M-Scale to create the composite metric; 
factor scores were obtained for each participant using the regression method. We used the composite metric factor scores to analyze the score difference at the M-Scale between $\mathrm{pTBI}$ and $\mathrm{HC}$. In addition, based on the factor scores, we constructed a lesion map of $\mathrm{pTBI}$ patients with an M-Scale score higher than 1 (high mysticism; $\mathrm{N}=14$ ) and lower than -1 (low mysticism, $N=14$ ) to identify lesion overlap in patients with high and low scores on the M-Scale. We deliberately chose the value 1 as a cutoff for mysticism since $\mathrm{HC}$ did not present average scores higher than 1 on that scale.

2.5. CT image acquisition and analysis. Axial CT scans were acquired on a GE Medical Systems Light Speed Plus CT scanner in helical mode, at the Bethesda Naval Hospital, Bethesda, MD. CT images were reconstructed with an in-plane voxel size of $0.4 \times 0.4 \mathrm{~mm}$, an overlapping slice thickness of $2.5 \mathrm{~mm}$ and $1-\mathrm{mm}$ slice interval. We used Analysis of Brain Lesion (ABLe v.2.8b) software (Makale, et al., 2002; Solomon, Raymont, Braun, Butman, \& Grafman, 2007) contained in MEDx v3.44 (Medical Numerics, Germantown, MD) to determine the lesion location and volume from CT images. Each CT image was spatially normalized to a CT template brain image in Montreal Neurological Institute (MNI) space (Collins, Neelin, Peters, \& Evans, 1994). We performed a spatial normalization with the automated image registration (AIR) algorithm (Woods, Grafton, Holmes, Cherry, \& Mazziotta, 1998), using a 12-parameter affine fit. Lesion volume was calculated by manually tracing the lesion in all CT slices, and then summing the traced areas and multiplying by slice thickness. A trained neuropsychiatrist performed the manual tracing, and was then reviewed by J.G., who was blind to the results of the clinical evaluation and neuropsychological assessment. 
At each voxel, a one-tailed t-test was used to compare the average score at the MScale between pTBI patients who had a lesion at a particular voxel and $\mathrm{HC}$. We restricted the analyses to a minimum overlap of 4 pTBI patients with lesions in a given voxel to ensure statistical power (Glascher, et al., 2009). We used a false discovery rate (FDR) correction for multiple comparisons with $\mathrm{q}=0.05$ (Genovese, Lazar, \& Nichols, 2002) to detect voxels with a statistically significant lesion-deficit relationship. Only clusters with a minimum of 10 adjacent voxels were reported. We quantified the percentage of AAL structures impacted by the lesion from the overlap of the normalized lesion images with the AAL atlas. In addition, we defined regions of interest (ROIs) in the dIPFC and temporal cortex, including posterior superior and middle gyrus (TC) as previously described (Gozzi, Raymont, Solomon, Koenigs, \& Grafman, 2009), by identifying AAL structures within specified ranges of MNI coordinates.

2.6. Lesion Mapping. VLSM was applied to the whole brain for the M-Scale factor scores. We used the automated anatomical labeling (AAL) atlas for gray matter (Tzourio-Mazoyer, et al., 2002) and the ICBM-DTI-81 atlas for white matter (Mori, et al., 2008) to identify the anatomical location of significant clusters.

\section{RESULTS}

3.1. Behavioral results. The $\mathrm{pTBI}$ and $\mathrm{HC}$ groups did not differ on demographics nor on most neuropsychological measures (Table 1). The pTBI group did have lower scores on the Sorting test; however their ranges were within the normal range. The pTBI group 
had a lower post-injury AFQT score than the HC group, but their scores were within the normal range (Grafman, et al., 1988).

\section{---Table 1 about here---}

Table 1. Demographics and neuropsychological measures (mean \pm s.d.) for penetrating traumatic brain injury patients (pTBI) and matched controls $(\mathrm{HC})$.

\begin{tabular}{|c|c|c|c|}
\hline Measure & pTBI $(\mathrm{N}=116)$ & $\mathrm{HC}(\mathrm{N}=32)$ & Statistics \\
\hline Age (years) & $63.28 \pm 2.89$ & $62.97 \pm 3.50$ & $t=.42, p=0.67$ \\
\hline Education (years) & $14.56 \pm 2.21$ & $15.13 \pm 2.17$ & $t=-1.29, p=0.21$ \\
\hline Handedness (R-L-A) & $93: 21: 2$ & $26: 4: 2$ & $x^{2}=2.37, p=0.25$ \\
\hline Pre-injury AFQT & $59.18 \pm 29.99$ & $57.80 \pm 33.00$ & $t=0.19, p=0.84$ \\
\hline Post-injury AFQT & $57.5=25 \pm 24.99$ & $72.97 \pm 19.77$ & $t=-3.18, p=0.002$ \\
\hline Verbal comprehension (TT) & $98.11 \pm 2.61$ & $98.55 \pm 1.84$ & $t=-1.07, p=0.37$ \\
\hline Object perception (VOSP) & $20.47 \pm 4.69$ & $21.35 \pm 3.33$ & $t=-1.19, p=0.23$ \\
\hline Depression (DBI2) & $7.22 \pm 7.54$ & $10.71 \pm 8.74$ & $t=-2.02, p=0.05$ \\
\hline Post-traumatic stress disorder (MPSTD) & $77.09 \pm 21.00$ & $83.10 \pm 22.52$ & $t=-1.33, p=0.18$ \\
\hline General Memory (WMS-III) & $98.76 \pm 15.00$ & $105.07 \pm 14.77$ & $t=-2.04, p=0.05$ \\
\hline Semantic Verbal Fluency (D-KEFS) & $9.04 \pm 3.18$ & $8.63 \pm 3.17$ & $t=0.62, p=0.53$ \\
\hline Card Sorting Test (D-KEFS) & $21.21 \pm 5.84$ & $24.73 \pm 5.47$ & $t=-3.08, p=0.003$ \\
\hline \multicolumn{4}{|l|}{ Neurobehavioral rating scale (NBRS) } \\
\hline - Disinhibition & $1.44 \pm 0.88$ & $1.42 \pm 0.76$ & $t=0.12, p=0.9$ \\
\hline - Hallucinatory Behavior & $1.02 \pm 0.29$ & $1.00 \pm 0.00$ & $t=0.63, p=0.52$ \\
\hline - Unusual Thought Content & $1.11 \pm 0.58$ & $1.00 \pm 0.00$ & $t=1.06, p=0.28$ \\
\hline
\end{tabular}


Table 1 AFQT, Armed Forces Qualification Test (percentile score); TT, Token Test for basic verbal comprehension; VOSP, Visual Object and Space Perception Battery for object and space perception (silhouettes); BDI2, Beck Depression Inventory 2 for depression; MPTSD, Mississippi post-traumatic stress disorder for post-traumatic stress disorder; WMS-III, Wechsler Memory Scale, abbreviated for immediate and delayed memory; D-KEFS, Delis Kaplan Executive Function System test for verbal fluency (we used the letter fluency total correct score, which is based on the number of correct words generated for each trial) and disinhibition (Card Sorting, we used the combined free sorting and sort recognition description score, which is based on the sum of correct description scores in the free sorting and sort recognition); subscales of the NBRS (Neurobehavioral rating scale) for disinhibition, hallucinatory behavior, and unusual thought.

The pTBI group $(M=0.11 S D=0.81,95 \% \mathrm{Cl}[-0.03,0.26])$ reported significantly more mystical experiences than the $\mathrm{HC}$ group $(M=-0.45, S D=0.85,95 \% \mathrm{Cl}[-0.75,-0.14])$ in the M-Scale factor scores $\mathrm{t}(146)=3.44 p=0.001, \eta_{p}^{2}=0.07$.

Epilepsy, especially of the right temporal lobe has been associated with religious/mystical experience (Dewhurst \& Beard, 1970; Persinger, 2001). In our participants, 40 pTBI patients had epilepsy $\left(\mathrm{E}_{+}\right), 64$ pTBI patients did not have epilepsy (E-), and $12 \mathrm{pTBI}$ had missing information concerning epilepsy. The pTBI $\mathrm{E}+(M=$ $0.001, S D=.85,95 \% \mathrm{Cl}[-0.27,0.27])$ and pTBI E- $(M=0.209, S D=0.82,95 \% \mathrm{Cl}[-$ $0.003,0.41])$ groups had similar M-Scale scores $\mathrm{t}(102)=1.22, p=0.224, \eta_{p}^{2}=0.01$. Pre- and post-injuries AFQT scores were not associated with mysticism scores and there were no significant correlations between AFQT scores and the M-scale (see Supplementary Table S1) in either group.

Due to the association between mysticism and depression (Ghorbani, Watson, \& Rostami, 2007), we controlled for the effects of depression on the M-scale and executive functions using as a measure of depression, the Beck Depression Inventory, 
Second Edition BDI-II (A. T. Beck, Steer, \& Brown, 1996). In our participants, 19 pTBI patients had depression ( $\mathrm{D}+$; score higher than 17 on the BDI-II scale), 93 pTBI patients did not have epilepsy (D-), and 4 pTBI had missing information concerning depression, $11 \mathrm{HC}$ had $\mathrm{D}+$ and $20 \mathrm{HC}$ had D-. The pTBI D+ $(\mathrm{M}=0.105, \mathrm{SD}=.81,95 \% \mathrm{Cl}[-0.18$, $0.60])$ and pTBI D- $(\mathrm{M}=0.209, \mathrm{SD}=0.81,95 \% \mathrm{Cl}[-0.06,0.27])$ groups had similar $\mathrm{M}-$ Scale scores $\mathrm{t}(110)=-.50, p=0.612, \eta_{p}^{2}=0.002$. In addition, the $p T B I D+(M=21.28$, $\mathrm{SD}=6.39,95 \% \mathrm{Cl}[19.90,22.33])$ and pTBI D- $(\mathrm{M}=21.11, \mathrm{SD}=5.77,95 \% \mathrm{Cl}[18.10$, 24.46]) groups had similar card sorting scores $\mathrm{t}(105)=-1.10, \mathrm{p}=0.914, \mathrm{n}^{2}<0.01$. Similarly, the $\mathrm{HC} D+(\mathrm{M}=0.105, \mathrm{SD}=.81,95 \% \mathrm{Cl}[-0.88,0.42])$ and $\mathrm{HC} \mathrm{D}-(\mathrm{M}=0.209$, $\mathrm{SD}=0.81,95 \% \mathrm{Cl}[-0.94,0.19])$ groups had similar M-Scale scores $\mathrm{t}(110)=-0.50, \mathrm{p}=$ $0.612, \eta_{p}^{2}=0.037$. In addition, the $\mathrm{HC} \mathrm{D}+(\mathrm{M}=23.00, \mathrm{SD}=7.28,95 \% \mathrm{Cl}[17.79$, 28.21]) and $\mathrm{HC} \mathrm{D}-(\mathrm{M}=25.42, \mathrm{SD}=4.31,95 \% \mathrm{Cl}[23.34,27.56])$ groups had similar card sorting scores $t(105)=-1.10, p=0.914, \eta_{p}^{2}=0.045$.

The Sorting test scores were associated with mysticism scores, indeed we found a negative correlation between Sorting test scores and the M-scale in the pTBI, but not in the HC, group (see Supplementary Table S1). Thus, lower mysticism was associated with higher executive function performance (problem-solving, see Supplementary Figure S2).

\subsection{Lesion results.}

Lesion density overlap maps are shown in Supplementary Figure S1. The maximum lesion overlap (20 patients) occurred in fronto-temporal regions and underlying white 
matter tracts. VLSM results for the M-Scale are shown in Figure 1. Since $9 \mathrm{HC}$ responded "yes" to the self-reported question about experiencing mysticism, we performed a supplementary VLSM analysis removing these participants. As shown in Figure 1 (B and Supplementary Table 2), results between the two analyses were similar. In order to increase the power of our analyses and decrease the imbalance between the $\mathrm{N}$ of the two groups ( $\mathrm{HC}$ and $\mathrm{pTBI})$, further analyses were performed using the entire $\mathrm{HC}(\mathrm{n}=32)$ group. Lesions in the frontal and temporal cortex were associated with higher scores on the M-Scale. These regions included the bilateral orbitofrontal cortex, bilateral dorsolateral prefrontal cortex (dIPFC), and right superior and inferior temporal cortex; as well as underlying white matter tracts including the superior corona radiata $(\mathrm{SCR})$, anterior corona radiata $(\mathrm{ACR})$, and posterior corona radiata $(\mathrm{PCR})$.

For a complete list of brain regions and MNI coordinates see Supplementary Table S2 (Supplementary).

As the pTBI group had higher M-Scale scores compared to HC group, we constructed a map indicating the lesion overlap of pTBI patients $(N=14)$ with $M$-Scores higher than 1 . pTBI patients with higher scores in the M-Scales showed the highest overlap of lesions in the right superior frontal gyrus [SFG] (see Figure 2A). In addition we constructed a lesion map of pTBI patients $(\mathrm{N}=14)$ with $\mathrm{M}$-Scores lower than -1 (quartile split) that showed the highest overlap of lesions in the right STG (superior temporal gyrus) and MTG (middle temporal gyrus) (see Figure 2B).

\section{---Figures 1 \& 2 about here---}

\section{Figure 1}




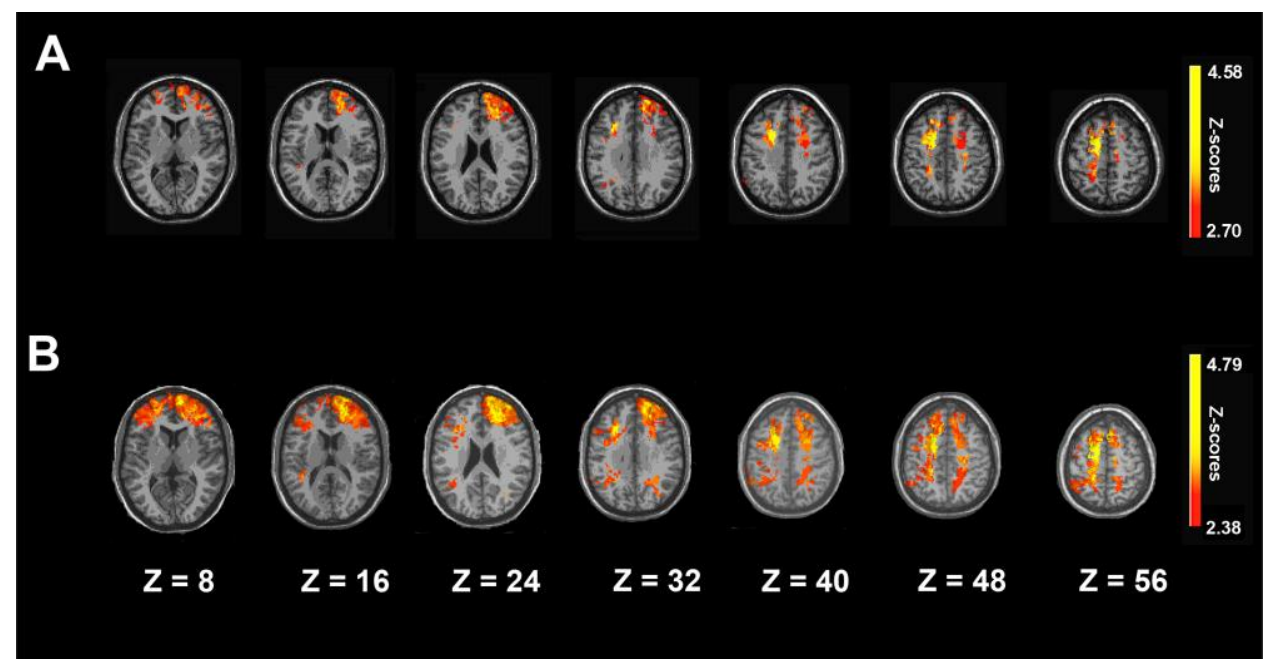

Figure 1 VLSM results with the Mysticism Score. VLSM compares voxel by voxel the performance of pTBI patients against all $\mathrm{HC}(\mathrm{A})$ and against $\mathrm{HC}$ without self-reported mystical experiences. The colored areas indicate a significant association between the presence of a lesion in that location and a higher score on the mysticism scale. Lesions within a fronto-temporal network were associated with higher scores on the M-Scale. Images are shown in radiologic convention: the right hemisphere is shown on the reader's left side. The color bar indicates z-scores.

Figure 2

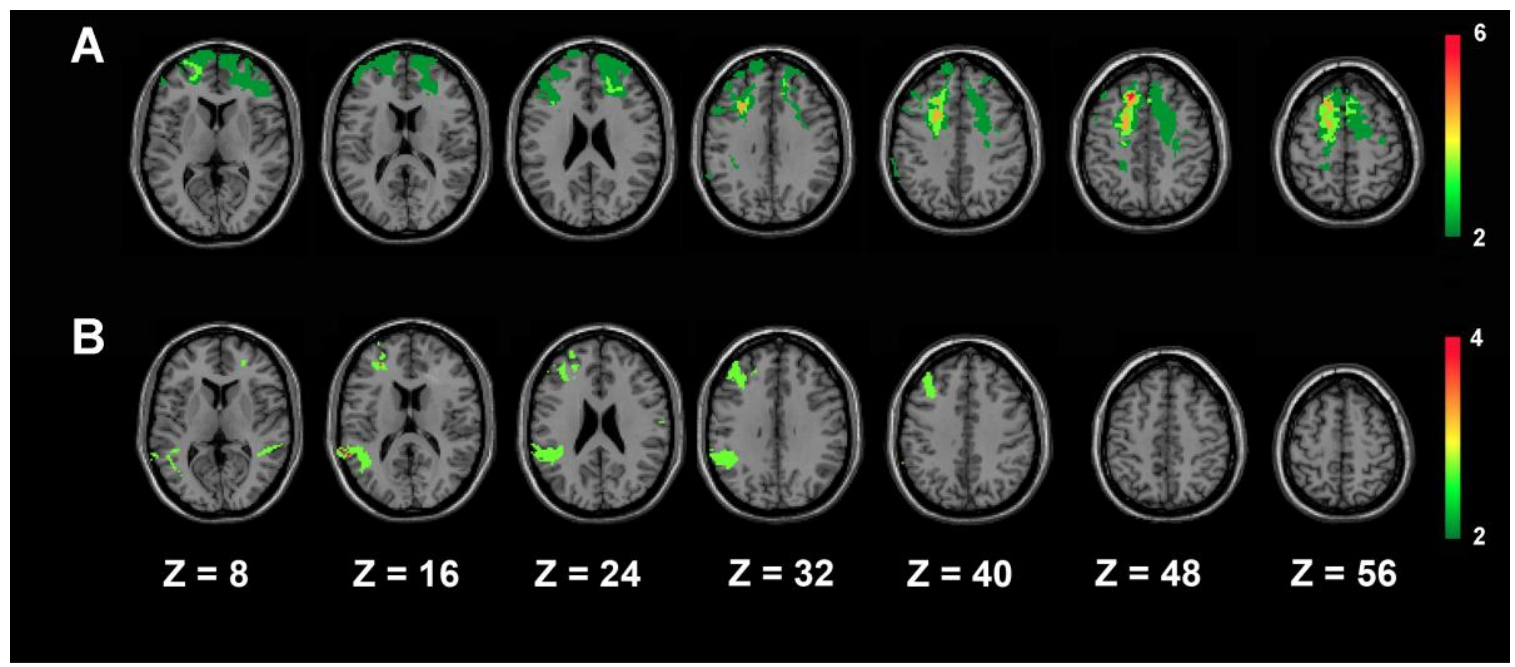

Figure 2 Map shows the lesions density overlap in pTBI patients with a mysticism score greater than $1(\mathrm{~N}=14, \mathrm{~A})$ and lower than $-1(\mathrm{~N}=14, \mathrm{~B})$. Color depicts the number of patients with the overlapping lesion at each voxel. Images are shown in radiologic 
convention: the right hemisphere is shown on the reader's left side. Color bar indicates overlapping patients.

Based on the VLSM exploratory results and previous theories about the brain regions/functions that mediate mystical experiences, we next targeted 2 groups of pTBI patients with focal lesions to the bilateral dIPFC $(\mathrm{N}=5)$, and right temporal cortex, including superior and middle temporal gyrus $(\mathrm{TC}, \mathrm{N}=8)$ and compared them to the $\mathrm{HC}$ ( $\mathrm{N}=32$ ) participants. The dIPFC, TC, and HC groups did not differ on neuropsychological measures, except for post-injury AFQT score; however, these scores were within the normal range (Grafman et al., 1988); the Card Sorting test was marginally significant (see Supplementary Table S3). Planned comparisons indicated that patients with a lesion to the dIPFC $(M=20.20, S D=2.77,95 \% \mathrm{Cl}[16.75,23.65])$ had a significantly lower score on the Sorting Test than $\mathrm{HC}(M=24.97, \mathrm{SD}=5.41,95 \%$ $\mathrm{Cl}[22.94,26.99]), t(42)=-2.84, p=0.017$, but not compared to the TC group $(M=$ $20.00, \mathrm{SD}=7.76,95 \% \mathrm{Cl}[18.25,27.76]), t(42)=-1.62, p>0.250$. No difference was found between TC and $\mathrm{HC}$ groups, $t(42)=0.61, p=0.140$. Figure 3 shows lesions density overlap for the dIPFC and TC groups (see Figure 3). A one-way ANOVA of the mean M-Scale score between the three groups showed a significant main effect, $F(2$, $42)=6.51, p<0.001, \eta_{p}^{2}=0.23$. The post-hoc comparison demonstrated that the mysticism score was significantly higher in the dIPFC group $(M=0.84, S D=1.04,95 \%$ $\mathrm{Cl}[-0.45,2.13])$, compared to the $\mathrm{HC}$ group $(M=-0.45, S D=0.85,95 \% \mathrm{Cl}[-0.30,0.96]$ see Figure 4), $p=0.010, \eta_{p}^{2}=0.01$, but not compared to the TC group $(M=0.33, S D=$ $0.76,95 \% \mathrm{Cl}[-0.75,-0.14]), p>0.250$. A marginally significant difference was found between the TC and MC groups, $p=0.080$. 


\section{---Figure 3 and 4 about here---}

Figure 3

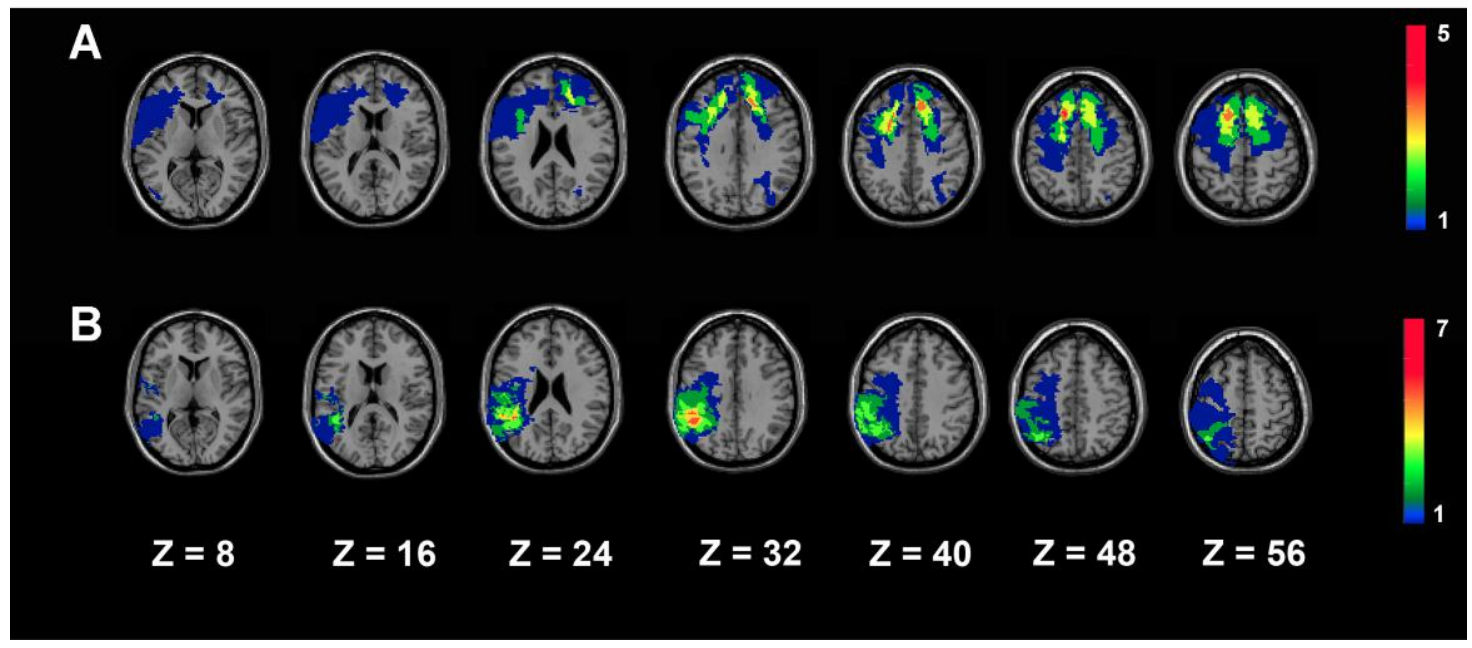

Figure 3 Map shows the overlap of the lesions in the dIPFC (BA 46, BA10, BA9), and TC (BA21, BA22) pTBI group. The maximum overlay is 6 for the dIPFC and 7 for the TC. Right hemisphere is shown on the left side.

\section{Figure 4}

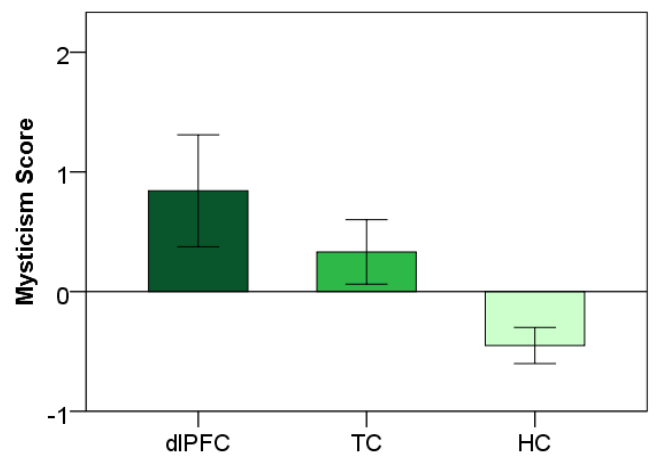

Figure 4 Mysticism average scores for the three groups: $\operatorname{dIPFC}(\mathrm{N}=5), \mathrm{TC}(\mathrm{N}=8)$, and $\mathrm{HC}(\mathrm{N}=32)$. The dIIPFC group had higher scores at the mysticism scale compared to $\mathrm{HC}(P=0.01)$. Error bars indicate $\pm 1 \mathrm{SE}$. 


\section{DISCUSSION}

The goal of this study was to test a causal model in which executive brain function underpins religious experience by investigating whether selective damage to brain regions that support executive processing leads to greater reported mystical experiences. It has also been theorized that the temporal lobes play a pivotal role in regulating mystical experience. To assess the causal contributions of these regions to mystical experience we administered the Mysticism scale to patients that included subgroups with damage to the dIPFC and temporal pole. Consistent with executive theories, we found that greater mystical experience was evident in those participants with lesions in the frontal and temporal regions. These regions include the dIPFC (BA 46, BA9, and BA10) and right superior and middle temporal cortices (BA21 and BA22), as well as underlying white matter tracts of the anterior, superior, and posterior corona radiata. After grouping our pTBI patients according to their scores on the Mysticism scale, we found that patients with higher scores had greater lesion overlap in the dIPFC; whereas patients with lower scores had greater lesion overlap in the right middle and superior temporal cortex. Finally, a confirmatory group analysis according to lesion location suggested that an intact dIPFC was required to regulate mysticism. Indeed, patients with focal lesions to the right temporal cortex did not differ from healthy controls on the mysticism score, while patients with focal lesions in the dIPFC had substantially higher mysticism scores compared to the controls. Collectively, these findings identify a homeostatic role of these brain regions with the dIPFC suppressing mystical experiences while regions within the temporal cortex, if unchecked, are more likely to produce mystical experience. 
Even though prior studies describe representations of God as mediated by the PFC via Theory of Mind processes (Kapogiannis, et al., 2009; Schjoedt, et al., 2009), recent studies suggest that mystical experiences may be induced by attenuating the executive functions of the PFC (Deeley, et al., 2014; Schjoedt, et al., 2011). We realize that religious experience may be complex, drawing on representational functions including theory of mind and at the same time facilitated by inhibition of executive processing. In any case, the executive functions theories we described support previous studies identifying inhibitory deregulation as a driver of mystical experience. It would be interesting to examine whether people might report mystical experiences without being able to represent God's mind.

Not only are our findings consistent with executive neuropsychological theories of mysticism, but also they agree with a wider body of research about executive brain functions. The dIPFC has been identified as critical for the cognitive control of attentional and emotional mechanisms (Davidson, Putnam, \& Larson, 2000; Miller \& Cohen, 2001; Ochsner \& Gross, 2005). Relatedly, several studies have revealed that the dIPFC assists in the down-regulation of emotional processing: for example, neuroimaging studies have reported increased dIPFC activity during awareness of neutral stimuli and suppression of fearful stimuli (Amting, Greening, \& Mitchell, 2010). Furthermore, studies using electrophysiological and/or functional neuroimaging techniques have reported consistently increased activity in the dIPFC during reappraisal (Kim \& Hamann, 2007; Ochsner, et al., 2004). Due to the role of dIPFC in emotional control and rationality, and supported by its connections with the temporal [see for a 
review (Goldman-Rakic, 1987)], we argue that the dIPFC has a critical role in regulating mystical experiences by binding context, deliberation, and rational experience to posterior cortices strongly affected by perceptual phenomena. In addition, the top-down regulation of the dIPFC on the temporal cortex was reported in previous studies involving many disparate processes such as working memory (see for a review (Simons \& Spiers, 2003)] and emotions (Banks, Eddy, Angstadt, Nathan, \& Phan, 2007; PenaGomez, Vidal-Pineiro, Clemente, Pascual-Leone, \& Bartres-Faz, 2011) via the tracts connecting those structures. Thus, the PFC has a crucial role in generating adaptive responses to ambiguous experience by the virtue of homeostatic regulatory principles [for a review see (Mizumori \& Jo, 2013)]. Importantly, we found that the pTBI group and the selective group of patients with lesions to the dIPFC had lower scores on the Sorting test. This is consistent with previous studies indicating that diminished executive functioning might be associated with the acceptance of religious beliefs (Schjoedt, et al., 2013). We must emphasize that the card sorting test measures not only executive control/inhibitory processes, but also concept-formation skills, modality-specific problem-solving skills, and the ability to explain concepts in an abstract manner. Thus, the association between disinhibition and mysticism, could be modulated by other complex process including abstraction and concept formation skills. Given the lack of a significant correlation between mysticism and verbal fluency or the AFQT percentile score, we have to limit our claim on the association between mysticism and executive (in this study a task requiring conceptual reasoning) and cognitive functions. The AFQT is not a direct measure of executive functioning, but a general cognitive measure that correlates highly with general intelligence (Grafman, et al., 1988). 
Religion has been associated with increased self-control. Mysticism, as a specific facet of religiosity, may be underpinned by different neural and cognitive processes. For instance McCullough \& Willoughby (2009) found that religion is associated with increased self-control (McCullough \& Willoughby, 2009). They reviewed 12 studies investigating this association and they found that 11 out 12 studies reported a positive correlation between self-reported religiosity and self-control or self-regulation. However, much of the research linking religion to self-control is correlational and therefore not able to shed definitive light on religion's ability to promote self-control. Another study from Inzlicht et al. (2009) indicated that religious individuals performed better on a Stroop task, but they had longer reaction times (Inzlicht, McGregor, Hirsh, \& Nash, 2009). Religion is associated with all sorts of restraints on behavior, and it has been speculated that repetitive religious practice, which appears to recruit the dorsal striatum, may encode alternative reward expectations (Bulbulia \& Schjoedt, 2013). Several studies also indicated that religious individuals that have mystical experiences are functional by any biological, cognitive, economic, and health measure (Coruh, Ayele, Pugh, \& Mulligan, 2005). How mystical experience — which looks so out of place compared to ordinary experience — is generated in the brain, then channeled, and contained - remains very poorly understood. Here, we find evidence consistent with a key role for forming concepts and the ability to inhibit in the induction of mystical experience. 
How might the temporal cortex be implicated in religious experiences such as mysticism? Patients suffering from temporal epilepsy often report mystical experiences (Devinsky, 2003; Devinsky \& Lai, 2008; Geschwind, 1983). In addition, recent neuroimaging studies found that remembering mystical experience was associated with right middle temporal lobe regions (BA 21) (Beauregard \& Paquette, 2006). This is consistent with our results, where a BA 21 lesion is associated with greater mysticism. This finding suggests that while the temporal lobe has an important role in generating mystical experience, the dIPFC has a critical role interpreting and modulating them. The VLSM analysis revealed that parietal cortex lesioned voxels were associated with a higher mysticism score. This result is consistent with previous studies that found reduced activity in the parietal cortex during meditation experiences, where participants felt a dissolution of the self, or the experience of an absolute unitary being (Newberg et al., 2001). Lesion to the parietal cortex might in this sense increase the opportunity to experience mystical episodes. A recent study from Urgesi et al. (2010) showed that damage to bilateral inferior parietal cortex was associated with self-transcendence, a stable personality trait measuring predisposition to spirituality (Urgesi, Aglioti, Skrap, \& Fabbro, 2010). It would have been of interest to examine the role of the parietal cortex in mystical experience, since the parietal lobe is also involved in inhibitory processes (Vivas, Humphreys, \& Fuentes, 2003). The lack of power given our few patients with selective lesion to the parietal cortex prevented us from creating a selective group of patients with focal lesion to the parietal cortex. Finally, while we controlled for epilepsy, it is possible that other medical or psychological conditions might have influenced the results. 
The present study addressed the question of whether executive functions underpin mystical experience. Speculating, we might also raise the more general question: why do mystical experiences implicate the frontal and temporal lobes? The following explanation seem plausible. If a subject were to have a perceptual experience that did not have a directly associated verbal explanation, our brain might default to a coarser contextual search for an explanation (Beeman, et al., 1994; R. W. Hood, Jr. \& Morris, 1981; Kounios \& Beeman, 2014). Though such defaulting would result in a slower cognitive process than would the direct explanatory path, the coarser (or divergent) search would have the benefit of allowing selection from multiple candidate explanations. A search could continue until the best fitting explanation for a perceptual experience was obtained. Notably, supernatural experiences, by definition, do not have direct explanations (i.e. we do not assume that supernatural phenomena causally account for mystical experiences, but rather that such experiences are endogenously and situationally generated). As a consequence, mystical experiences might benefit from a coarser contextual search, and as such benefit from attenuated prefrontal cortical representational processes. If the superior PFC were damaged, subjects might simply assume that their perceptual experiences were not grounded in the physical world, and as such, default to a confabulated mystical or supernatural explanation (Bulbulia, 2009).

Our study also confirmed previous evidence indicating the importance of white matter integrity for normative social and cognitive behavior (Cristofori, et al., 2015; Karlsgodt, 
et al., 2009; Ludlow, et al., 1986). Indeed, we found that higher mysticism was related also to white matter structures bonding PFC and temporal cortex, such as the posterior corona radiata, and white matter structures bonding PFC and subcortical regions, such the anterior corona radiata.

In this report, we investigated the causal contribution of cortical regions and underlying white matter structures to mystical experiences by drawing on a large and unique sample of older male war veterans who sustained brain injuries during combat. This unique sample allowed us to better understand the causal forces of selective brain regions on mystical experience related to religious belief. Here, we find an association that supports a model in which the causal underpinning of mystical experience is due in part to executive disinhibition. As with most belief domains where culture and cognition intersect, we expect that multiple cognitive processes underpin mystical experiences. Inferences from this study must be evaluated in its context. We have no measure of religiosity prior to warfare; cortical damage was, for of obvious reasons, not selectively applied; cortical processing is, at any rate, both diffuse and robust: functions initially perturbed by local damage may be restored partially or completely through neural plasticity mechanisms. The novelty of the paper comes from its efficient leveraging of information afforded by a large sample of combat veterans who underwent a rigorous cognitive assessment at military induction, who were systematically exposed to the conditions of war, and some of whom, very unfortunately, were subject to penetrating brain injuries. We used these intelligence test measures pre/post combat, as well as accepted measures of religiosity, to test theories about the role of executive functions in 
mystical experience. It is import to emphasize that a role for executive functions is supported by the several studies on religion and executive regulation we reviewed in the introduction.

In our study, we did not find any association between executive function measures and mystical experiences, except for the card-sorting test. Therefore, the evidence for a link between a wide range of executive function measures and mystical experience is weak. Instead we found that the card sorting test alone showed this relationship. In addition, we did not find between-group differences on observed disinhibition (using the Neurobehavioral Rating Scale (NBRS; Levin, et al., 1987), hallucinatory behaviors, and unusual thoughts.

The participants in this study were studied between 40 to 45 years after their injury and surely patients were stable by then since most of the compensatory mechanisms observed after TBI had likely occurred in the 3 years immediately post-injury (Han, et al., 2007). We could not control for severity of the injury since the injury occurred before instruments assessing TBI severity were widely used (e.g., the Glasgow Coma Scale was introduced in 1974 (Teasdale \& Jennett, 1974). We also were unable to time the CT scan around the mystical experience.

Further studies could investigate how other factors contribute to the experience of mysticism such as genetic predisposition or ecological and social context influences (Botero, et al., 2014); as well as how mystical experiences influence cognitive and social processes. 
To conclude, our findings identified a homeostatic role of different components of a frontal and temporal cortex in regulating mystical experience. In particular, we speculate that the dIPFC has a crucial role in providing a rational explanation of an experience that otherwise might be described as mystical. More generally, our results could imply that the dIPFC constrains naïve interpretations of the basis and meaning of perceptual experiences. In doing so, it modifies our experience of the world and our interpretation of compelling but not easily explained perceptual phenomena.

\section{AKNOWLEDGEMENTS}

We thank our dedicated Vietnam veterans for their invaluable participation in the study. We also thank G. J. Solomon for his assistance with ABLe, as well as V. Raymont, S. Bonifant, B. Cheon, C. Ngo, A. Greathouse, K. Reding, and G. Tasick for testing and evaluating participants. Lastly, we thank the National Naval Medical Center and the National Institute of Neurological Disorders and Stroke for their support and provision of their facilities. The US Department of Education (M. Switzer Research Fellowship: ID: H133F130009) supported IC. A Templeton World Charity Foundation Grant (ID: 0077) and a Royal Society of New Zealand Marsden Grant (ID: VUW1321) supported JB and JS. The views expressed in this article are those of the authors and do not necessarily reflect the official policy or position of the Department of the Navy, the Department of Defense, or the U.S. Government.

Conflict of interest. None declared. 
Author contributions: J.B., F.K., M. W., and J.G. designed and performed research; I.C., J.B, and J.S. analyzed data; and I.C., J.B., J.S., F.K., and J.G wrote the paper. 


\section{REFERENCES}

AFQT-7A. (1960). Department of Defense Form 1293, March 1.

Alcorta, C. S., \& Sosis, R. (2005). Ritual, emotion and sacred symbols: The evolution of religion as an adaptive complex. Human Nature: An Interdisciplinary Biosocial Perspective, 16, 323-359.

Amting, J. M., Greening, S. G., \& Mitchell, D. G. (2010). Multiple mechanisms of consciousness: the neural correlates of emotional awareness. J Neurosci, 30, 10039-10047.

Andersen, M., Schjoedt, U., Nielbo, K., \& Sorensen, J. (2014). Mystical experience in the lab. Method and Theory in the Study of Religion, 26, 217-245.

Aron, A. R., Robbins, T. W., \& Poldrack, R. A. (2004). Inhibition and the right inferior frontal cortex. Trends Cogn Sci, 8, 170-177.

Banks, S. J., Eddy, K. T., Angstadt, M., Nathan, P. J., \& Phan, K. L. (2007). Amygdala-frontal connectivity during emotion regulation. Soc Cogn Affect Neurosci, 2, 303-312.

Barrett, J. L., \& Keil, F. C. (1996). Conceptualizing a non-natural entity: anthropomorphism in God concepts. Cogn. Psychol, 31, 219-247.

Beauregard, M., \& Paquette, V. (2006). Neural correlates of a mystical experience in Carmelite nuns. Neurosci Lett, 405, 186-190.

Beck, A. T., Steer, R. A., \& Brown, G. K. (1996). BDI-II, Beck Depression Inventory: Manual Boston: Harcourt Brace.

Beck, A. T., Steer, R. A., Brown, G. K., \& (1996). Beck Depression Inventory Manual (Ed 2. ed.). San Antonio.

Beeman, M., Friedman, R. B., Grafman, J., Perez, E., Diamond, S., \& Lindsay, M. B. (1994). Summation priming and coarse semantic coding in the right hemisphere. $J$ Cogn Neurosci, 6, 26-45.

Benson, D. F., \& Stuss, D. T. (1990). Frontal lobe influences on delusions: a clinical perspective. Schizophr Bull, 16, 403-411.

Botero, C. A., Gardner, B., Kirby, K. R., Bulbulia, J., Gavin, M. C., \& Gray, R. D. (2014). The ecology of religious beliefs. Proc Natl Acad Sci U S A, 111, 16784-16789.

Brugger, P., \& Mohr, C. (2008). The paranormal mind: How the study of anomalous experiences and beliefs may inform cognitive neuroscience. Cortex, 44, 1291-1298.

Bulbulia, J. (2009). Religiosity as mental time travel: cognitive adaptations for religious behavior. New York, NY: Oxford University Press.

Bulbulia, J., \& Schjoedt, U. (2012). Toward an evolutionary social neuro- science of religion. Religion, Brain \& Behavior, 1, 220-222.

Bulbulia, J., \& Schjoedt, U. (2013). The neural basis of religion. In F. K. a. J. Grafman (Ed.), The neural basis of human belief systems (pp. 169-190). New York: Psychology Press.

Cassotti, M., \& Moutier, S. (2010). How to explain receptivity to conjunction-fallacy inhibition training: evidence from the lowa gambling task. Brain Cogn, 72, 378-384.

Collins, D. L., Neelin, P., Peters, T. M., \& Evans, A. C. (1994). Automatic 3D intersubject registration of MR volumetric data in standardized Talairach space. J Comput Assist Tomogr, 18, 192-205.

Corbetta, M., \& Shulman, G. L. (2002). Control of goal-directed and stimulus-driven attention in the brain. Nat Rev Neurosci, 3, 201-215.

Coruh, B., Ayele, H., Pugh, M., \& Mulligan, T. (2005). Does religious activity improve health outcomes? A critical review of the recent literature. Explore (NY), 1, 186-192.

Cristofori, I., Viola, V., Chau, A., Zhong, W., Krueger, F., Zamboni, G., \& Grafman, J. (2015). The Neural Bases for Devaluing Radical Political Statements Revealed by Penetrating Traumatic Brain Injury. Soc Cogn Affect Neurosci. 
Cutting, J. (1987). The phenomenology of acute organic psychosis. Comparison with acute schizophrenia. Br J Psychiatry, 151, 324-332.

D’Aquili, E., \& Newberg, A. B. (1993). Religious and Mystical States: A Neuropsychological Substrate. Zygon, 28, 177-200.

Dal Monte, O., Schintu, S., Pardini, M., Berti, A., Wassermann, E. M., Grafman, J., \& Krueger, F. (2014). The left inferior frontal gyrus is crucial for reading the mind in the eyes: Brain lesion evidence. Cortex, 58, 9-17.

Davidson, R. J., Putnam, K. M., \& Larson, C. L. (2000). Dysfunction in the neural circuitry of emotion regulation--a possible prelude to violence. Science, 289, 591-594.

Deeley, Q. (2003). Social, Cognitive, and Neural Constraints on Subjectivity and Agency: Implications for Dissociative Identity Disorder. Philosophy, Psychiatry, and Psychology, 10, 161-167.

Deeley, Q., Oakley, D. A., Walsh, E., Bell, V., Mehta, M. A., \& Halligan, P. W. (2014). Modelling psychiatric and cultural possession phenomena with suggestion and fMRI. Cortex, 53, 107-119.

Delis, D. C., Kaplan, E., \& Kramer, J. H. (2001). The Delis Kaplan Executive Function System: Examiner's manual. San Antonio, TX: The Psychological Corporation.

Devinsky, O. (2003). Psychiatric comorbidity in patients with epilepsy: implications for diagnosis and treatment. Epilepsy Behav, 4 Suppl 4, S2-10.

Devinsky, O., \& Lai, G. (2008). Spirituality and religion in epilepsy. Epilepsy Behav, 12, 636-643.

Dewhurst, K., \& Beard, A. W. (1970). Sudden religious conversions in temporal lobe epilepsy. Br J Psychiatry, 117, 497-507.

Dietrich, A. (2003). Functional neuroanatomy of altered states of consciousness: the transient hypofrontality hypothesis. Conscious Cogn, 12, 231-256.

Friedman, N. P., \& Miyake, A. (2004). The relations among inhibition and interference control functions: a latent-variable analysis. J Exp Psychol Gen, 133, 101-135.

Genovese, C. R., Lazar, N. A., \& Nichols, T. (2002). Thresholding of statistical maps in functional neuroimaging using the false discovery rate. Neuroimage, 15, 870-878.

Geschwind, N. (1983). Interictal behavioral changes in epilepsy. Epilepsia, 24 Suppl 1, S23-30.

Ghorbani, N., Watson, P. J., \& Rostami, R. (2007). Relationship of self-reported mysticism with depression and anxiety in Iranian Muslims. Psychol Rep, 100, 451-454.

Glascher, J., Tranel, D., Paul, L. K., Rudrauf, D., Rorden, C., Hornaday, A., Grabowski, T., Damasio, H., \& Adolphs, R. (2009). Lesion mapping of cognitive abilities linked to intelligence. Neuron, 61, 681-691.

Goldman-Rakic, P. S. (1987). Circuitry of primate prefrontal cortex and regulation of behaviour by representational memory (Vol. 5). Washington, DC: The American Physiological Society.

Gozzi, M., Raymont, V., Solomon, J., Koenigs, M., \& Grafman, J. (2009). Dissociable effects of prefrontal and anterior temporal cortical lesions on stereotypical gender attitudes. Neuropsychologia, 47, 2125-2132.

Grafman, J., Jonas, B. S., Martin, A., Salazar, A. M., Weingartner, H., Ludlow, C., Smutok, M. A., \& Vance, S. C. (1988). Intellectual function following penetrating head injury in Vietnam veterans. Brain, 111 ( Pt 1), 169-184.

Han, S. D., Drake, A. I., Cessante, L. M., Jak, A. J., Houston, W. S., Delis, D. C., Filoteo, J. V., \& Bondi, M. W. (2007). Apolipoprotein E and traumatic brain injury in a military population: evidence of a neuropsychological compensatory mechanism? J Neurol Neurosurg Psychiatry, 78, 1103-1108.

Hood, R. W., Hill, P. C., \& Spilka, B. (2009). The psychology of religion: An empirical approach. . New York: Guilford Press.

Hood, R. W., Jr. (1975). The construction and preliminary validation of a measure of reported mysticalexperience. Journal for the Scientific Study of Religion, 14. 
Hood, R. W., Jr., \& Morris, R. J. (1981). Sensory isolation and the differential elicitation of religious imagery in intrinsic and extrinsic persons. Journal for the Scientific Study of Religion, 20, 261-273.

Inzlicht, M., McGregor, I., Hirsh, J. B., \& Nash, K. (2009). Neural markers of religious conviction. Psychol Sci, 20, 385-392.

Kapogiannis, D., Barbey, A. K., Su, M., Zamboni, G., Krueger, F., \& Grafman, J. (2009). Cognitive and neural foundations of religious belief. Proc Natl Acad Sci U S A, 106, 4876-4881.

Karlsgodt, K. H., Sanz, J., van Erp, T. G., Bearden, C. E., Nuechterlein, K. H., \& Cannon, T. D. (2009). Re-evaluating dorsolateral prefrontal cortex activation during working memory in schizophrenia. Schizophr Res, 108, 143-150.

Keane, T. M., Caddell, J. M., \& Taylor, K. L. (1988). Mississippi Scale for Combat-Related Posttraumatic Stress Disorder: three studies in reliability and validity. J Consult Clin Psychol, 56, 85-90.

Kim, S. H., \& Hamann, S. (2007). Neural correlates of positive and negative emotion regulation. $J$ Cogn Neurosci, 19, 776-798.

Koechlin, E., Ody, C., \& Kouneiher, F. (2003). The architecture of cognitive control in the human prefrontal cortex. Science, 302, 1181-1185.

Kounios, J., \& Beeman, M. (2014). The cognitive neuroscience of insight. Annu Rev Psychol, 65, 71-93.

Levin, H. S., High, W. M., Goethe, K. E., Sisson, R. A., Overall, J. E., Rhoades, H. M., Eisenberg, H. M., Kalisky, Z., \& Gary, H. E. (1987). The neurobehavioural rating scale: assessment of the behavioural sequelae of head injury by the clinician. $J$ Neurol Neurosurg Psychiatry, 50, 183-193.

Lindeman, M., Svedholm, A. M., Riekki, T., Raij, T., \& Hari, H. (2013). Is it just a brick wall or a sign from the universe? An fMRI study of supernatural believers and skeptics. Soc Cogn Affect Neurosci, 8, 943-949.

Ludlow, C. L., Rosenberg, J., Fair, C., Buck, D., Schesselman, S., \& Salazar, A. (1986). Brain lesions associated with nonfluent aphasia fifteen years following penetrating head injury. Brain, 109 ( Pt 1), 55-80.

Luhrmann, T. (2005). The art of hearing god: absorption, dissociation, and contemporary american spirituality. Spiritus, 5, 133-157.

Luhrmann, T. (2012). When God talks Back: Understanding the American Evangelical Relationship with God.

Makale, M., Solomon, J., Patronas, N. J., Danek, A., Butman, J. A., \& Grafman, J. (2002). Quantification of brain lesions using interactive automated software. Behav Res Methods Instrum Comput, 34, 6-18.

McCullough, M. E., \& Willoughby, B. L. (2009). Religion, self-regulation, and self-control: Associations, explanations, and implications. Psychol Bull, 135, 69-93.

McNeil, M. M., \& Prescott, T. E. (1994). Revised Token Test. Los Angeles, CA.

Miller, E. K., \& Cohen, J. D. (2001). An integrative theory of prefrontal cortex function. Annu Rev Neurosci, 24, 167-202.

Mizumori, S. J., \& Jo, Y. S. (2013). Homeostatic regulation of memory systems and adaptive decisions. Hippocampus, 23, 1103-1124.

Mori, S., Oishi, K., Jiang, H., Jiang, L., Li, X., Akhter, K., Hua, K., Faria, A. V., Mahmood, A., Woods, R., Toga, A. W., Pike, G. B., Neto, P. R., Evans, A., Zhang, J., Huang, H., Miller, M. I., van Zijl, P., \& Mazziotta, J. (2008). Stereotaxic white matter atlas based on diffusion tensor imaging in an ICBM template. Neuroimage, 40, 570-582.

Newberg, A. B., Wintering, N. A., Morgan, D., \& Waldman, M. R. (2006). The measurement of regional cerebral blood flow during glossolalia: a preliminary SPECT study. Psychiatry Res, 148, 67-71. 
$\mathrm{Ng}, \mathrm{F}$. (2007). The interface between religion and psychosis. Australas Psychiatry, 15, 62-66.

Nigg, J. T. (2000). On inhibition/disinhibition in developmental psychopathology: views from cognitive and personality psychology and a working inhibition taxonomy. Psychol Bull, 126, 220-246.

Ochsner, K. N., \& Gross, J. J. (2005). The cognitive control of emotion. Trends Cogn Sci, 9, 242-249.

Ochsner, K. N., Ray, R. D., Cooper, J. C., Robertson, E. R., Chopra, S., Gabrieli, J. D., \& Gross, J. J. (2004). For better or for worse: neural systems supporting the cognitive down- and up-regulation of negative emotion. Neuroimage, 23, 483-499.

Pena-Gomez, C., Vidal-Pineiro, D., Clemente, I. C., Pascual-Leone, A., \& Bartres-Faz, D. (2011). Down-regulation of negative emotional processing by transcranial direct current stimulation: effects of personality characteristics. PLoS One, 6, e22812.

Persinger, M. A. (2001). The neuropsychiatry of paranormal experiences. J Neuropsychiatry Clin Neurosci, 13, 515-524.

Previc, F. H. (2006). The role of the extrapersonal brain systems in religious activity. Conscious Cogn, 15, 500-539.

Raymont, V., Salazar, A. M., Krueger, F., \& Grafman, J. (2011). "Studying injured minds" - the Vietnam head injury study and 40 years of brain injury research. Front Neurol, 2, 15.

Saver, J. L., \& Rabin, J. (1997). The neural substrates of religious experience. $J$ Neuropsychiatry Clin Neurosci, 9, 498-510.

Schjoedt, U., Sørensena, J., Nielboa, K. L., Xygalatasa, D., Mitkidisa, M., \& Bulbulia, J. (2013). Cognitive resource depletion in religious interactions. Religion, Brain \& Behavior, 3, 3986.

Schjoedt, U., Stodkilde-Jorgensen, H., Geertz, A. W., Lund, T. E., \& Roepstorff, A. (2011). The power of charisma--perceived charisma inhibits the frontal executive network of believers in intercessory prayer. Soc Cogn Affect Neurosci, 6, 119-127.

Schjoedt, U., Stodkilde-Jorgensen, H., Geertz, A. W., \& Roepstorff, A. (2009). Highly religious participants recruit areas of social cognition in personal prayer. Soc Cogn Affect Neurosci, 4, 199-207.

Simons, J. S., \& Spiers, H. J. (2003). Prefrontal and medial temporal lobe interactions in longterm memory. Nat Rev Neurosci, 4, 637-648.

Solomon, J., Raymont, V., Braun, A., Butman, J. A., \& Grafman, J. (2007). User-friendly software for the analysis of brain lesions (ABLe). Comput Methods Programs Biomed, $86,245-254$

Stace, W. T. (1960). Mysticism and Philosophy. New York.

Teasdale, G., \& Jennett, B. (1974). Assessment of coma and impaired consciousness. A practical scale. Lancet, 2, 81-84.

Tzourio-Mazoyer, N., Landeau, B., Papathanassiou, D., Crivello, F., Etard, O., Delcroix, N., Mazoyer, B., \& Joliot, M. (2002). Automated anatomical labeling of activations in SPM using a macroscopic anatomical parcellation of the MNI MRI single-subject brain. Neuroimage, 15, 273-289.

Urgesi, C., Aglioti, S. M., Skrap, M., \& Fabbro, F. (2010). The spiritual brain: selective cortical lesions modulate human self-transcendence. Neuron, 65, 309-319.

Vivas, A. B., Humphreys, G. W., \& Fuentes, L. J. (2003). Inhibitory processing following damage to the parietal lobe. Neuropsychologia, 41, 1531-1540.

Warrington, E. K., \& James, M. (1991). The Visual Object and Space Perception Battery.

Wechsler, D. (1997). Wechsler Memory Scale III. San Antonio, TX: Psychological Corporation.

Wildman, W. J. (2011). Religious and Spiritual Experiences. Cambridge, U.K.

Woods, R. P., Grafton, S. T., Holmes, C. J., Cherry, S. R., \& Mazziotta, J. C. (1998). Automated image registration: I. General methods and intrasubject, intramodality validation. $J$ Comput Assist Tomogr, 22, 139-152. 
